\title{
ORIGINAL
}

ARTICLES

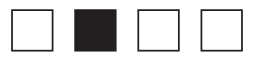

\section{Teaching Chronic Pain in the Family Medicine Residency}

Kimberly Zoberi, MD; Kelly M. Everard, PhD

BACKGROUND AND OBJECTIVES: Chronic pain is a significant condition affecting many Americans. Primary care physicians play an important role in chronic pain management, but many residents and physicians feel poorly prepared to manage it.

METHODS: Data were collected as part of the 2016 Council of Academic Family Medicine Educational Research Alliance (CERA) Program Director Survey, which was sent electronically to 484 program directors in the United States. The authors sought to determine whether residency directors' attitudes about treating chronic pain were associated with the amount of time devoted to teaching family medicine residents about chronic pain assessment, therapy (use of opioids, use adjuvant pain medications, use of other nonopioids, use of nonpharmacological treatments), and risk management (risk assessment, use of pain management contracts, informed consent when prescribing opioids, and urine drug monitoring). Attitudes were assessed by asking whether: (1) chronic pain is best managed by a primary care physician (PCP); (2) prescribing opioid medications is time consuming; (3) prescribing opioids is high-risk; (4) prescribing opioids contributes to opioid misuse; and (4) effective nonopioid treatments exist. An additional question assessed confidence in treating chronic pain.

RESULTS: The response rate was $53 \%$. The average family medicine residency devotes about 33 hours to education about pain management topics including 5.4 hours on chronic pain assessment, 16.2 hours on therapy, and 11.4 hours on risk assessment. Residency directors' belief that there are effective nonopioid treatments for chronic pain was the only attitude item that was associated with teaching about chronic pain.

CONCLUSIONS: Residency directors' attitudes do not predict the time devoted to teaching chronic pain in family medicine residencies.

(Fam Med. 2018;50(1):22-7.)

doi: 10.22454/FamMed.2018.134727

hronic pain currently affects more than 100 million Americans, ${ }^{1}$ causing economic impact of $\$ 560-665$ billion per year. ${ }^{2}$ Chronic pain is associated with multiple negative effects, including mood disorders, ${ }^{3}$ sleep impairment, ${ }^{4}$ and decreased quality of life. ${ }^{5}$ Despite the significance of chronic pain, patients face economic barriers, with pain management specialists accepting only certain forms of insurance. Most chronic pain patients receive pain management services from their primary care physicians. ${ }^{8}$

Because of their commitment to the biopsychosocial model, family physicians are ideally suited to treat complicated problems such as chronic pain, ${ }^{9}$ but require adequate training in this field. Primary care physicians cite a desire to manage their own patients with chronic pain, with support from pain management specialists as needed..$^{10}$ Family medicine educators call for standardized, high-quality family medicine residency education in chronic pain management, and for family physicians to assume a leadership role in pain management education. ${ }^{9}$

Despite the high patient demand for pain management services and the benefits of having primary care physicians manage their own patients, training in pain management is inadequate at both the medical school ${ }^{11,12}$ and residency levels..$^{11,13}$ A majority of practicing physicians rated their pain management training as inadequate,${ }^{14}$ and confidence in their ability to treat chronic pain is low. ${ }^{15} \mathrm{~A}$ survey of residents found that only $17 \%$ felt "confident" or "very confident" in their ability to treat patients with chronic to pain management specialists is not an option, as there are far too few pain management physicians to meet this need. ${ }^{1,7}$ Patients may also
From the Department of Family Medicine, Saint Louis University School of Medicine. 
nonmalignant pain. In addition, providers cite pessimism about their ability to help chronic pain patients and concerns about addiction, diversion, and legal risk as reasons for their negative attitude toward pain management. ${ }^{7}$

There is evidence that participation in a multidisciplinary, family medicine-run clinic may improve family medicine residents' satisfaction with treating chronic pain patients. Residents who participated in this clinic showed more enjoyment in patient interactions and optimism about patient outcomes. ${ }^{16}$

Data on pain management curricula for family medicine residencies are lacking. A 2008 survey collected data from residency programs representing various specialties ${ }^{17}$ and found that only $57 \%$ of residency directors reported offering any curriculum in pain management. There are comprehensive chronic pain management curricular guidelines for family medicine residents, ${ }^{18}$ but these guidelines reflect the recommended curriculum, not what is done in actual residency education. The guidelines also do not quantify the total number of hours recommended, nor the breakdown of time allotted to various subtopics.

A previous survey found that half of all family medicine clerkships were not teaching about chronic pain at all. The only personal characteristic of clerkship directors which correlated with teaching about chronic pain was the director's confidence in caring for chronic pain patients. ${ }^{19}$ Our exploratory study set out to determine whether residency directors' attitudes about treating chronic pain were associated with the amount of time devoted to teaching family medicine residents about different chronic pain topics.

\section{Methods}

The questions were part of a larger omnibus survey conducted by the Council of Academic Family Medicine Educational Research Alliance (CERA). ${ }^{20}$ The CERA steering committee evaluated questions for consistency with the overall subproject aim, readability, and existing evidence of reliability and validity. Pretesting was done on family medicine educators who were not part of the target population. Questions were modified following pretesting for flow, timing, and readability. The project was approved by the American Academy of Family Physicians Institutional Review Board in December 2015. Data were collected from July to August, 2016.

The sampling frame for the survey was all Accreditation Council for Graduate Medical Education (ACGME) accredited US family medicine residency program directors as identified by the Association of Family Medicine Residency Directors (AFMRD). Email invitations to participate were delivered with the survey utilizing the online program SurveyMonkey. Four follow-up emails to encourage nonrespondents to participate were sent after the initial email invitation. There were 495 program directors at the time of the survey. Eleven had previously opted out of CERA surveys. The survey was emailed to 484 individuals. Nine emails could not be delivered, nine individuals opted out of the survey, and one individual replied that she was no longer a program director. The final sample size was therefore 465. The overall response rate for the survey was $53.7 \%$ (245/465).

\section{Survey Questions}

Respondents answered questions about their programs including type of residency, size of the community in which their program is located, number of accredited residency slots, and years as program director. Additional items asked how much time the program's curriculum devoted to formal, didactic teaching about the following chronic pain topics: pain assessment, use of opioids, use adjuvant pain medications, use of other nonopioids, use of nonpharmacological treatments, risk assessment, use of pain management contracts, informed consent when prescribing opioids, and urine drug monitoring. Attitudes toward treating chronic pain were measured by asking clerkship directors to rate their agreement to the following statements on a scale from 1 to 5 (where 1 is strongly disagree and 5 is strongly agree): "Chronic pain is a disease state best managed in a primary care office"; "Prescribing opioid medications is time consuming for a primary care physician"; "Prescribing opioids is a high-risk clinical activity for a primary care physician"; "Prescribing opioids contributes to the opioid misuse epidemic in our society"; "There are effective nonopioid treatments for chronic pain"; "Multiple effective treatments exist for treating chronic pain, and I am confident that I am personally skilled in treating chronic pain."

\section{Analyses}

Frequencies describe type of residency, community size in which program is located, number of accredited residency slots, years as program director, the attitude measures, and hours teaching about chronic pain topics. Using SPSS version 20, independent samples $t$-tests were used to determine whether attitudes about treating chronic pain were associated with amount of time teaching about the different chronic pain topics.

\section{Results}

The final sample size for the entire survey was 245 , with an overall response rate of $53.7 \%$ (245/465). Descriptive statistics for program and program director characteristics are summarized in Table 1. Most programs were community-based and university-affiliated and had between 19 and 31 residents. The greatest amount of time was spent teaching about chronic pain assessment, and the least amount of time was spent teaching about informed consent when prescribing opioids. Nearly all respondents agreed that opioid prescribing practices have contributed to the opioid misuse epidemic in our society (94.1\%). Just over half (54.9\%) agreed they were confident in their skills for treating 
chronic pain (Table 2). Table 2 contains the descriptive statistics for hours teaching about the pain topics and attitudes toward chronic pain treatment.

For the $t$-test analyses using the attitude items, we combined the "strongly agree" and "agree" responses into one "agree" category and the "strongly disagree," "disagree," and "neutral" responses into one "do not agree" category. The actual number of hours allotted to teaching was used in the analyses, except when respondents chose "greater than 20 hours", which was the highest option the survey allowed respondents to choose. We recoded "greater than 20 hours" as "20 hours" and used this new variable in our analyses. We calculated a variable for total hours teaching about therapy by adding the hours teaching about opioids, nonopioids, nonpharmacological treatments, and adjuvant pain
Table 1: Descriptive Statistics for Residency Programs Program Director Characteristics

\begin{tabular}{|l|c|}
\hline \multicolumn{1}{|c|}{ Program Type } & \\
\hline Community-based, university-affiliated & $64.5 \%$ \\
\hline University-based & $16.9 \%$ \\
\hline Community-based, nonaffiliated $\quad$ Community Size & $11.2 \%$ \\
\hline Military & $5.0 \%$ \\
\hline & \\
\hline Less than 30,000 Residency Slots & $7.0 \%$ \\
\hline 30,000 to 74,999 & $16.0 \%$ \\
\hline 75,000 to 149,000 & $17.3 \%$ \\
\hline 150,000 to 499,999 & $28.0 \%$ \\
\hline 500,000 to 1 million & $16.5 \%$ \\
\hline More than 1 million & $15.2 \%$ \\
\hline & \\
\hline Less than 19 & $33.3 \%$ \\
\hline 19 to 31 & $48.4 \%$ \\
\hline Greater than 31 & $17.3 \%$ \\
\hline & $\mathbf{M}$ (SD) \\
\hline Years as program director & $6.13(6.0)$ \\
\hline
\end{tabular}

Table 2: Hours Teaching Pain Topics and Percent Agreement with Attitudes Toward Chronic Pain Items

\begin{tabular}{|c|c|c|}
\hline Hours Teaching & M (SD) Individual Items & $\begin{array}{l}\text { M (SD) Combined } \\
\text { Items }\end{array}$ \\
\hline Assessment & & $5.4(4.5)$ \\
\hline Chronic pain assessment & $5.4(4.5)$ & \\
\hline Therapy & & $16.2(14.5)$ \\
\hline Use of opioids & $4.9(4.2)$ & \\
\hline Nonpharmacological treatments & $4.2(4.5)$ & \\
\hline Use of adjuvant pain meds & $3.7(3.7)$ & \\
\hline Use of nonopioids & $3.6(3.7)$ & \\
\hline Risk Management & & $11.4(12.9)$ \\
\hline Risk assessment & $3.2(3.6)$ & \\
\hline Pain management contract & $3.2(3.5)$ & \\
\hline Urine drug monitoring & $2.8(3.4)$ & \\
\hline Informed consent & $2.4(3.2)$ & \\
\hline Attitude Items & $\%$ Agree & \\
\hline $\begin{array}{l}\text { Opioid prescribing practices have contributed to the opioid misuse } \\
\text { epidemic in our society. }\end{array}$ & $94.1 \%$ & \\
\hline $\begin{array}{l}\text { Prescribing opioid medications is time consuming for a primary care } \\
\text { physician. }\end{array}$ & $84.1 \%$ & \\
\hline $\begin{array}{l}\text { Prescribing opioids is a high risk clinical activity for a primary care } \\
\text { physician. }\end{array}$ & $74.1 \%$ & \\
\hline There are effective, nonopioid treatments for chronic pain. & $72.8 \%$ & \\
\hline Chronic pain is a disease state best managed in a primary care office. & $67.6 \%$ & \\
\hline Multiple effective treatments exist for treating chronic pain & $61.5 \%$ & \\
\hline I am confident that I am personally skilled in treating chronic pain. & $54.9 \%$ & \\
\hline
\end{tabular}


medications. We calculated a variable for teaching about risk management by adding the hours teaching about pain management contracts, urine drug monitoring, risk assessment, and informed consent. The hours devoted to teaching about assessment of chronic pain were measured using the single item. These three variables assessing time spent teaching, therapy, risk management, and risk assessment, were used in the $t$-tests with the attitude measures.

Two attitude items were not used in analysis because most respondents agreed with the statements. For "opioid prescribing practices contribute to misuse", $94.1 \%$ of respondents agreed, and $84.1 \%$ agreed that "prescribing opioid medications is time consuming." Respondents who agreed that there are effective nonopioid treatments for chronic pain spent more time in their programs teaching about therapy for chronic pain (17.8 hours vs 12.0 hours, $P<.0001)$ and pain assessment (5.7 hours vs 4.4 hours, $P=.026$ ) than those who did not agree. Those who agreed that multiple effective treatments exist for treating chronic pain spent more time teaching about therapy for chronic pain (17.7 hours vs 13.9 hours, $P=.032$ ) than respondents who did not agree. Respondents who agreed that chronic pain is best managed in a primary care office had programs that spent fewer hours teaching about risk management (10.1 hours vs 14.3 hours, $P=.048$ ) than those who did not agree. Our exploratory study set out to determine whether attitudes about chronic pain treatment influenced the amount of time spent teaching about chronic pain. However, when we used a Bonferroni adjusted $P$ value of .003 to account for multiple comparisons, only one of these findings remained significant (Table 3).

\section{Discussion}

Family medicine residency programs devote an average of 33 hours to various chronic pain topics including pain assessment, various therapies, and risk management. This number varied widely, with programs reporting a range of 2 hours to 180 hours in total curriculum.

One significant finding of this paper is that program directors' belief in the existence of effective nonopioid treatments for chronic pain is associated with more hours teaching about chronic pain therapy (teaching about use of opioids, nonpharmacologic treatments, adjuvant pain medications, or nonopioids.) The total number of hours spent teaching about opioids (4.9 hours) was only slightly higher than the number of hours spent teaching about other therapeutic options, including nonpharmacologic treatment (4.2 hours), adjuvant pain medications (3.7 hours), and nonopioid pain medication (3.6 hours.) Family medicine residencies are teaching about multiple aspects of chronic pain therapy, and opioid prescribing is not the overwhelming majority of the chronic pain treatment curriculum. Similarly, the total number of hours spent on risk management issues (11.4 hours) is much less than the total number of hours spent on the combined assessment and management of chronic pain (21.6 hours combined total).

There was no significant association between the belief that chronic pain is best managed in a primary care office and hours teaching about any aspect of chronic pain. In fact, there was a trend toward an inverse association between this belief and hours teaching about risk management. Perhaps a positive attitude toward chronic pain management in primary care may lead to fewer hours spent teaching about the negative aspects of pain management, such as risk management (which included risk assessment, use of pain contracts, informed consent, and drug monitoring.) A previous educational intervention demonstrated that exposure to chronic pain patients in a patient-centered medical home pain clinic improved residents' attitudes toward chronic pain patients. ${ }^{21}$ It is unclear whether a positive attitude on the part of the residency director influences how the pain management curriculum is taught. Further investigation is needed.

Although we hypothesized that attitudes of program directors toward chronic pain issues would influence the number of hours taught in their programs, little association was found. Nearly all program directors (94\%) agreed that opioid prescribing practices have contributed to the current opioid misuse epidemic in society, and most agreed (84\%) that prescribing opioids is a timeconsuming undertaking for primary care physicians. The nearly unanimous endorsement of the idea that opioid prescribing has contributed to the opioid epidemic may suggest discomfort with the way that opioid prescribing has previously been conducted. Previous studies have shown that physicians' negative attitudes about opioids influences prescribing. ${ }^{22}$

A limitation of this study was the modest response rate. About half of residency directors chose not to respond to the survey. It is possible that nonrespondents had stronglyheld attitudes or beliefs about the role of chronic pain management in residency education, and that these attitudes or beliefs influence curriculum design. In addition, because this survey asked residency directors to self-report the hours of education on various pain management topics, it is possible that recall was inaccurate or biased.

This survey explored the amount and content of chronic pain management in the family medicine residency curriculum. Family medicine residents rotating in other specialties such as surgery, ICU, and emergency medicine may get additional pain management content in those rotations. Similarly, there were no questions about residents' self-directed learning on this topic. This survey showed that family medicine programs are educating their residents about chronic pain assessment, 
Table 3: Hours Teaching About Therapy, Risk Management, and Chronic Pain Assessment by Attitudes Toward Treatment

\begin{tabular}{|c|c|c|c|}
\hline & \multicolumn{3}{|c|}{ Hours Teaching About Therapy } \\
\hline & $\begin{array}{l}\text { Agree } \\
\text { M (SD) }\end{array}$ & $\begin{array}{l}\text { Do Not Agree } \\
\text { M (SD) }\end{array}$ & $P$ Value \\
\hline $\begin{array}{l}\text { Prescribing opioids is a high-risk clinical activity for a primary } \\
\text { care physician. }\end{array}$ & $16.4(15.4)$ & $15.8(11.7)$ & .805 \\
\hline There are effective, nonopioid treatments for chronic pain. & $17.8(16.1)$ & $12.0(7.5)$ & $<.0001^{*}$ \\
\hline $\begin{array}{l}\text { Chronic pain is a disease state best managed in a primary care } \\
\text { office. }\end{array}$ & $15.6(13.2)$ & $17.7(17.0)$ & .302 \\
\hline $\begin{array}{l}\text { I am confident that I am personally skilled in treating chronic } \\
\text { pain. }\end{array}$ & $16.9(15.6)$ & $15.1(12.7)$ & .343 \\
\hline \multirow[t]{3}{*}{ Multiple, effective treatments exist for treating chronic pain. } & $17.7(16.5)$ & $13.9(10.1)$ & .032 \\
\hline & \multicolumn{3}{|c|}{ Hours Teaching About Risk Management } \\
\hline & $\begin{array}{l}\text { Agree } \\
\text { M (SD) }\end{array}$ & $\begin{array}{l}\text { Do Not Agree } \\
\text { M (SD) }\end{array}$ & $P$ Value \\
\hline $\begin{array}{l}\text { Prescribing opioids is a high-risk clinical activity for a primary } \\
\text { care physician. }\end{array}$ & $11.6(13.9)$ & $11.0(9.4)$ & .779 \\
\hline There are effective, nonopioid treatments for chronic pain. & $12.3(14.3)$ & $9.2(7.7)$ & .105 \\
\hline $\begin{array}{l}\text { Chronic pain is a disease state best managed in a primary care } \\
\text { office. }\end{array}$ & $10.1(10.2)$ & $14.3(17.0)$ & .048 \\
\hline $\begin{array}{l}\text { I am confident that I am personally skilled in treating chronic } \\
\text { pain. }\end{array}$ & $11.7(13.5)$ & $11.0(11.9)$ & .673 \\
\hline \multirow[t]{3}{*}{ Multiple, effective treatments exist for treating chronic pain. } & $12.4(14.2)$ & $10.0(9.9)$ & .174 \\
\hline & \multicolumn{3}{|c|}{ Hours Teaching About Pain Assessment } \\
\hline & $\begin{array}{l}\text { Agree } \\
\text { M (SD) }\end{array}$ & $\begin{array}{l}\text { Do Not Agree } \\
\text { M (SD) }\end{array}$ & $P$ Value \\
\hline $\begin{array}{l}\text { Prescribing opioids is a high-risk clinical activity for a primary } \\
\text { care physician. }\end{array}$ & $5.25(4.4)$ & $5.8(5.0)$ & .444 \\
\hline There are effective, nonopioid treatments for chronic pain. & $5.74(4.8)$ & $4.4(3.6)$ & .026 \\
\hline $\begin{array}{l}\text { Chronic pain is a disease state best managed in a primary care } \\
\text { office. }\end{array}$ & $5.2(3.9)$ & $5.7(5.6)$ & .302 \\
\hline $\begin{array}{l}\text { I am confident that I am personally skilled in treating chronic } \\
\text { pain. }\end{array}$ & $5.5(4.6)$ & $5.2(4.4)$ & .537 \\
\hline Multiple, effective treatments exist for treating chronic pain. & $5.7(5.0)$ & $4.8(3.7)$ & .102 \\
\hline
\end{tabular}

*Significant at .003. Bonferroni adjustment of $P$ value to account for multiple comparisons.

therapy, and risk management. However, personal characteristics and attitudes of the program director largely failed to predict which programs would include a greater number of hours on this curriculum, or which aspects of the curriculum would be included.

Future research should clarify the specific pain management topics currently being taught in family medicine residencies compared to topics in recommended curricula guidelines. More detail is needed on how residents are being educated about various therapeutic options, including the use of NSAIDs, adjuvant pain medications, and other nonopioid pain management options. This survey found near universal agreement with the statement that "Opioid prescribing practices have contributed to the opioid misuse epidemic in our society." However, it is not clear what action should therefore result, or whether instruction at the residency level can mitigate this epidemic. Similarly, a large majority of residency directors agreed with the statement that prescribing opioids is time consuming, but strategies for managing this challenge remain an issue for further research.

CORRESPONDING AUTHOR: Address correspondence to Dr Zoberi, Saint Louis University School of Medicine, Department of Family and Community Medicine, 1402 Grand Blvd, St Louis, MO 63104. 314-977-8480. Fax: 314-9775268. kimberly.zoberi@health.slu.edu. 


\section{References}

1. Institute of Medicine, Relieving Pain in America: A Blueprint for Transforming Prevention, Care, Education, and Research. Washington, DC: The National Academies Press; 2011.

2. Gaskin, D.J. and P. Richard, The economic costs of pain in the United States. J Pain. 2012. 13(8): 715-724.

3. Von Korff M, Crane P, Lane M, et al. Chronic spinal pain and physical-mental comorbidity in the United States: results from the national comorbidity survey replication. Pain. 2005. 113(3):331-339.

4. Marty M, Rozenberg S, Duplan B, et al. Quality of sleep in patients with chronic low back pain a case-control study. Eur Spine J. 2008. 17(6): 839-844.

5. McCarberg BH, Nicholson BD, Todd KH, Palmer T, Penles L. The impact of pain on quality of life and the unmet needs of pain management: results from pain sufferers and physicians participating in an Internet survey. Am J Ther. 2008. 15(4):312-320

6. Survey conducted for the American Pain Society, The America Academy of Pain Medicine, and and Janssen Pharmaceutica, Chronic Pain in America: Roadblocks to Relief. Hanson, NY: Roper Starch Worldwide; 1999.

7. Potter M, Schafer S, Gonzalez-Mendez E, et al. Opioids for chronic nonmalignant pain - attitudes and practices of primary care physicians in the UCSF/Stanford Collaborative Research Network. J Fam Pract. 2001. 50(2):145-151.

8. Breuer B, Cruciani R, Portenoy RK, Pain management by primary care physicians, pain physicians, chiropractors, and acupuncturists: a national survey. South Med J. 2010. 103(8): 738-747.

9. STFM Group on Pain Management and Palliative Care. Pain Education in Family Medicine. 2008.

10. Wiedemer, Harden PS, ARndt IO, Gallagher $\mathrm{RM}$. The opioid renewal clinic: a primary care, managed approach to opioid therapy in chronic pain patients at risk for substance abuse. Pain Med. 2007. 8(7): 573-584.
11. Darer JD, Hwang W, Pham HH, Bass EB, Anderson G. More training needed in chronic care: a survey of US physicians. Acad Med. 2004. 79(6): 541-548.

12. Mezei L, Murinson BB, Johns Hopkins Pain Curriculum Development Team. Pain education in North American medical schools. J Pain. 2011. 12(12): 1199-1208.

13. Lippe PM, Brock C, David J, Crossno R, Gitlow S, The First National Pain Medicine Summitfinal summary report. Pain Med. 2010. 11(10): 1447-1468

14. Upshur CC, Luckmann SS, and Savageau JA Primary care provider concerns about management of chronic pain in community clinic populations. J Gen Intern Med. 2006. 21(6): 652-655.

15. O'Rorke JE, Chen I, Genao I, Panda M, Cykert S. Physicians' comfort in caring for patients with chronic nonmalignant pain. Am J Med Sci. 2007. 333(2): 93-100

16. Evans L, Whitham JA, Trotter DR, Filtz KR An evaluation of family medicine residents' attitudes before and after a PCMH innovation for patients with chronic pain. Fam Med. 2011 43(10): 702-711.

17. Ogle KS, McElroy L, Mavis B. No relief in sight: postgraduate training in pain management. Am J Hosp Palliat Care. 2008. 25(4) 292-297.

18. American Academy of Family Physicians. Reprint No. 286 Recommended Curriculum Guidelines for Family Medicine Residents Chronic Pain Management. http://www.aafp. org/dam/AAFP/documents/medical_education residency/program_directors/Reprint286_Pain. pdf. Accessed August 2017.

19. Zoberi KS, Everard KM, Antoun J. Teaching chronic pain in the family medicine clerkship: influences of experience and beliefs about treatment effectiveness: a CERA study. Fam Med. 2016. 48(5): 353-358.
20. Mainous AG 3rd, Seehusen D, Shokar N. CAFM Educational Research Alliance (CERA) 2011 Residency Director survey: background, methods, and respondent characteristics. Fam Med. 2012. 44(10): 691-693.

21. Anandarajah G, Furey C, Chandran R, et al. Effects of adding a new PCMH block rotation and resident team to existing longitudinal training within a certified PCMH: primary care residents' attitudes, knowledge, and experience. Adv Med Educ Pract. 2016. 7: 457-466.

22. Wilson HD, Dansie EJ, Kim MS, Moskovitz BL, Chow W, Turk DC. Clinicians' attitudes and beliefs about opioids survey (CAOS): instrument development and results of a national physician survey. J Pain. 2013. 14(6): 613-627. 